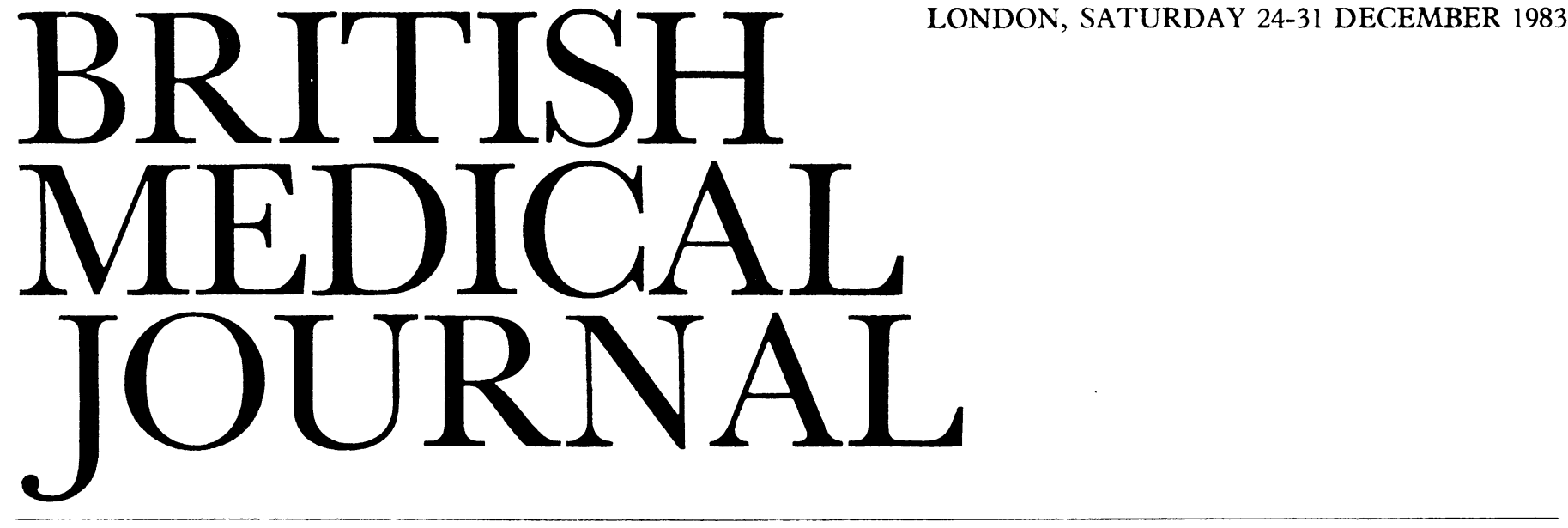

\title{
Open letter to the new CMO
}

\section{Dear Donald,}

As our new Chief Medical Officer at the Department of Health and Social Security, you will bring to the job the originality, zest, and humour that you have shown in your earlier career. But at the risk of boring you and adding to an already large pile of suggestions may I send you my own good wishes and thoughts for the New Year. I have put these under five headings without implying any priority among them, and anyway virtually all of them are interconnected.

\section{Hospital service}

The decline of Britain's hospital service began when Barbara Castle was Secretary of State for Health. The enmity between the ancillary workers and the consultants was succeeded by the former obtaining unjustified powerbreaking the camaraderie that had existed for decades, undermining the geographical whole time concept, and destroying morale among the hospital specialists, driving many of them to get their major satisfactions elsewhere, often in private practice.

Rhetoric, some might say, and certainly failure of management nerve is not universal-but where it has occurred (as at many of our teaching hospitals) the evidence is clear: the offhand, unkempt porter at the gate, the grubby corridors, the stained and torn upholstery, the unswept car parks, the vandalised lifts; the nurses still overworked, despite the large number of assistants who were supposed to relieve them of the chores; the surgeon who can no longer start his list at the time he used to because of the diktat of the local shop steward. Alternatively, there is the evidence in the recent introduction to a lecture, The New Genetics and Clinical Practice, by somebody who is hardly a rabid medical politician. "This essay was written," writes David Weatherall, Nuffield professor of medicine at Oxford, "during a period when morale in the clinical schools and National Health Service fell to an all time low. Perhaps it was futile to hope to attempt to raise any enthusiasm for another piece of irrelevant, high technology medicine in a country which apparently is too poor to provide adequate services for its handicapped, be they young or old."

All these problems are recent and they have clouded much of your predecessor's time (incidentally apparently diminishing
Henry Yellowlees's considerable achievements). As a newcomer, you can give them prominence and restore the management's determination to manage; this should be easier with the government's new policy on industrial relations. First of all, a central decision needs to be taken on whether the Health Service's priority is to provide good patient care or as many lowly jobs as possible, the pay off being that the wages are often appalling but that those appointed are not expected to do very much and so are little supervised; British Rail is not alone in having had to make a similar decision-that the customer is more important than the porter-before it could even begin to look at new investment and plans for the future. Pilot studies of privatisation may show new paths to efficiency in the NHS, and its application incidentally might also produce valuable spin offs: pilfering, for example-a neglected but important factor in hospital budgets-costs millions of pounds every year; how many dialysis treatments would this pay for? Such pilfering is often considerably reduced when private laundry services take over, and privately provided meals are often cheaper and better.

So I hope that you will agree with me that studies on privatisation are well worth while, that it should be adopted where it leads to greater efficiencies, but that efficient happy ships should be left undisturbed. This is not to start a witch hunt and create yet more unemployment-merely to recognise that the NHS is better off trying to do one task well-that of looking after its patients humanely and efficiently-than doing two, potentially conflicting, tasks badly.

The Health Service is far from overmanned in all departments; and the savings you make with some reductions in the ancillary (and possibly administrative) posts should be used to increase the numbers of some other workers-particularly the clinical nurses. Nurses now get more time off and an increasing number have been diverted to administrationso that, although the number of nurses has risen considerably, the amount of time spent in clinical work has not risen proportionately. Add to this the demands of the new technology and the strain is only too obvious, particularly at nights and weekends. The same could be said for a few other groups.

Our doctors, too, deserve to be able to practise medicine of the same high standards as the rest of the civilised world. After 35 years of the Health Service we still have not made the adequate universal throughout the land. Waiting lists are long, much longer in some parts of Britain than in others; 
the standards of perinatal and geriatric care still vary enormously throughout a region and among different regions; and, to quote the usual example of how far Britain lags behind, every year we allow 2000 of our citizens to die needlessly of terminal kidney failure which could be treated with dialysisand would be in virtually every other Western country. And in that context, it is shameful, I believe, that the Health Service has come to rely for service needs on money from private charities such as the British Kidney Patients Association, the British Heart Foundation, the National Society for Cancer Relief, and the Imperial Cancer Research Fund. These and other charities are paying the salaries of NHS staff in an attempt to maintain adequate services for specific groups of patients.

At a time when many health areas are closing beds and rationing surgeons' supplies of pacemakers, lenses, and artificial joints resentment is growing about examples of conspicuous and nonsensical waste. Small, outdated, uneconomic hospitals are kept open against the wishes of health authorities in response to intensive emotional lobbying. In how many cities has the planned new district hospital, with all specialist services on one site, been postponed time and again? Building programmes stop, start, and stop again, perpetuating the fragmentation of services among several hospitals within one city with patients shuttled around at a great expense of time, money, and medical frustration. Once a clear plan has been agreed for building a new hospital to replace one or more obsolete structures every month's delay is expensive-yet delays are imposed in desperate attempts to balance budgets. Surely an efficient and humane organisation should establish some sort of rolling programme for finishing half built hospitals, financed initially from a special fund and paid for subsequently out of closing the other hospitals down and increased efficiency.

If these changes are not made then I believe the effect will be a significant shift to private practice. Few challenge the justification of a small private health sector-it can be a useful yardstick for NHS standards-but for several reasons many would be dismayed by a large increase: among these damaging effects are the exclusion of some categories of illness, the high administrative costs, and the further separation of Britain into two nations; but the most important would be the disastrous effects on the NHS. We have an indifferent standard of state secondary education in Britain, I believe, largely because of a vicious circle, in which the middle class has used private schools, and, because of the absence of middle class interest and pressure, the state schools have failed to improve, whereupon the middle class has gone on using private schools. So far in health we have avoided this dual standard, and in consequence the NHS, and in particular the individual patient, has benefited.

\section{Family practice}

Your initial task in family medicine must be to implement what you have proposed in your report on tackling the problems of the inner cities. The $£ 9$ million just allocated will not go far in solving the problem of aging doctors, often practising singlehandedly, poor though expensive premises, little intellectual stimulation, and inadequate ancillary help, not to mention the necessity of having to live away from the unattractive and vandalised city centres. It will be up to you to ensure that this money is spent wisely, to try to start experiments in various different forms of practice, and to obtain more money for the various practices if the project is a success. You had a large hand in the pump priming exercise by the University Grants Committee, which earmarked money for three new chairs in general practice based on inner city areas. This is an imaginative and cost effective example of what can be done.

Otherwise, however, general practice is in good shape, showing the versatility that makes it so attractive to many of our best medical graduates. It is likely to remain so until it encounters the same strict financial constraints that are applied to the rest of the NHS, for until now, recognising it for the bargain that it is, governments have in effect been willing to allow many types of community care open ended finance. Already, however, some commentators are pointing out that the cost of some types of community care may be approaching those of residential care, though of course the funds come out of different budgets.

Please encourage GPs to go on taking work that they can do just as well away from the hospitals-follow up and diabetic clinics, and minor surgery, for instance-for it represents another bargain. GPs, I hope, will also play an increasing part in patient self help schemes and health education, for here is another important, efficient, and cost effective role. Prevention must be one of the important planks in your campaign for better health, and through GPs you need to go on hammering home the messages that we all want conveyed-about the enormous toll of the preventable: cigarette smoking, obesity, and alcohol. The public will respond and so eventually will parliament (look at seat belts, even if your Secretary of State did vote against the bill).

Unfortunately, so far as prevention is concerned, your Under Secretary of State, John Patten, put up a lamentable performance after the publication of the recent Royal College of Physicians report on smoking-and you will have to try a new approach. One might be to convince your counterparts in other government departments of the evils of smoking and how, for example, sport and the arts ought to be seeking other sources of sponsorship (which are there, whatever they say). And how about approaching the head of the Civil Service and persuading him to show official disapproval of the tobacco industry by instructing individual civil servants to shun its invitations such as the reputed wining and dining at Wimbledon and Glyndebourne?

\section{Manpower}

We are always being reminded that the Health Service is the largest employer in Europe and that three quarters of its budget goes on salaries, giving the authorities virtually no flexibility at all. Yet manpower is also the NHS's most flexible resource; ways must be found to encourage all staff-and that includes consultants as well as shop stewards-to respond positively to the challenges of providing good health care in a changing environment rather than just digging in their heels and protecting their narrow interests.

I suspect that much of your time on manpower will be taken up purely with doctors, and here close links with the University Grants Committee and the General Medical Council will be valuable. To look at those parts of Europe where large numbers of doctors are unemployed-Italy and Spain, for example-the strategic answer for Britain is inescapable: cut the number of medical students and end the system whereby medical schools are paid a sort of capitation fee, so that big equals rich. Short term, however, Britain has to end its overdependence on overseas doctors (but at the same time introduce the proposed sponsorship (NODSO) 
scheme for them), see that everybody who qualifies gets preregistration jobs, and ensure greater mobility among those already in career posts. Shouldn't you get the profession to have a serious look at the retirement ages for various types of doctor? Isn't it time that the profession examined again the pattern of senior posts in hospital ? Shouldn't you seek to ban academic units with sources of income of their own from creating those "honorary" registrar and senior house officer posts which have done so much to snarl up the manpower figures and undermine sensible planning?

Finally, you will realise that I have left unmentioned your own specialty of community medicine. This means no disrespect but the specialty has taken such a battering in the past few years that it needs calm to find a new role, in which I hope epidemiology will feature prominently.

\section{Economies}

Much of what has been suggested will save no money, or may even cost some more, and anyway the NHS needs another $1^{0}$ a year in real terms just to stay still. We need both symbolic savings and real ones. A prime candidate for the former must be prescribing, but here I hope that you will look at the experience of the countries that have tried desperate remedies and not listen to the scrannel pipes of those who want to bash what is largely a responsible, valuable, and essential industry. Instead, you should give a deadline to a committee of representatives from the profession, the royal colleges, the postgraduate centres, and the industry to come up with suggestions for sensible savings.

Large scale savings could be made from increased efficiency, and the Griffiths report has pointed out the scope for this. We need to encourage more rigorous audit in all branches of medicine, to expand the number of courses on management for doctors (not forgetting national courses for treasurers and senior clinical nurses, for whom these should be mandatory), and to sponsor pilot schemes of new management ideas in a district or region. One of the prime tasks must be to get much better data; if only record linkage, which you pioneered at Oxford, had been applied to the whole country how much better things would be today.

Nevertheless, enthusiasm for such ideas will not persist unless the individual can see what his unit is getting out of his efforts. Making savings to accommodate generalised cuts is destructive of morale; being told "you can build a new day centre if you find the money" is quite different. Morale also suffers a devastating blow when political pressures reverse a decision that has been logically and properly taken-witness the absurd "rent a nob" campaign over Tadworth Hospital, which is still costing the NHS thousands of pounds a month for 20 convalescent children, who could equally well be catered for elsewhere. Most importantly, there is the grinding down effect of streams of documents, recommendations, and orders. How can a service as complex as the NHS be properly managed when the rules are changing all the time? If the principle is really to allow local decision making why insist that a financial cut has to be made in terms of manpower, when the solutions must be individual? Thorough audit, not constant interference, should be the method of ensuring efficiency and maintaining it.

\section{Communications}

Not only does the DHSS shower the periphery with paper, thereby confounding the important with the trivial, but its communications are poor. To be polite, the press office is less than adequate (not for nothing does the press call the DHSS the Department of Stealth and Total Obscurity) and Health Trends lacks lustre. In particular I hope that you will see that the former is prompt in dispatching information but also ensures that all interested organisations receive it, and review whether Health Trends is really necessary; if so why not change it into a lively newsheet telling everybody what is going on ? (look at the Museums Bulletin for a good example). Lastly, please see that all letters to the Department are answered promptly and fully.

Good luck to you in all this. You have the intellect, the background, and the courage (challenging some years ago, with the BMY's help, no less an institution than the membership examination of the Royal College of Physicians). But please don't lose sight of Britain's wider responsibilitiesparticularly to the Third World, by arranging guaranteed rotating medical posts there from Britain and seeing that the teaching of medicine appropriate to those countries-including "tropical medicine" - is properly organised here.

The profession is willing to help you, for you are (or should be) an invaluable channel for medical views and advice to reach not only ministers but also your non-medical colleagues in Whitehall. Don't forget also that you have a responsibility to speak back frankly to the profession about unacceptable practices-underuse of facilities, cancelling outpatient services, and overreliance on deputising services, for example.

In the end, of course, many of the important decisions are going to be purely political; but some of these may go your way. It is not unlikely, for example, once our population realises how far our standards have slipped behind the rest of the world, that there will be overwhelming pressure to spend less on armaments and more on the elderly. When that comes about the NHS will be in good shape under your guidance to turn these decisions into reality.

\section{Don't call us ...}

$B M 7$ editors each have three phones and in their early days they think-mistakenly - that this implies high status. "Can you excuse me a moment ?" we say smugly when speaking on one phone and another rings. If the third then rings as well pride mingles with irritation-but only in the noviciate months.

With the souring effects of time the occasions multiply in which repeated calls on all three phones enrage the editor attempting to compose 1000 words to meet a deadline. "Can you tell me whether it is safe to irradiate bananas?" asks one caller. Another wants to discuss his paper, rejected ten days (and one hundred papers) ago; a third believes he is talking to the Lancet.

Slowly it dawns that real status comes from being unreachable on the phone: you can't ring up Mrs Thatcher or President Reagan and ask them to explain why they are putting nuclear missiles half a mile from your back door. Real status is also not having to make your own calls. "Just give the $B M F$ a ring and ask them if they know how important this paper they're rejecting really is," the busy neurosurgeon tells his temporary secretary, who's too scared to ask what the $B M \mathcal{F}$ is and what paper he's talking about. We riposte by just giving the author a ring to ask him if he really meant $10 \mathrm{mg}$ of digoxin. 